\title{
APONTAMENTOS CRÍTICOS SOBRE A COLONIALIDADE DO SABER: EM DEFESA DA PLURALIDADE NA CONSTRUÇÃO DO CONHECIMENTO
}

\author{
Naiara Cristina Santos de Souza ${ }^{1}$ \\ André Marques do Nascimento ${ }^{2}$
}

\section{RESUMO}

Neste artigo, problematizamos sobre como o modelo de produção de conhecimento eurocêntrico marginaliza outras epistemologias em nome das alegadas neutralidade e racionalidade instauradas pela geopolítica do conhecimento no mundo moderno/colonial. Interessa-nos, a partir dos estudos decoloniais, discutir como a violência epistêmica é perpetuada, principalmente, através da estruturação da própria universidade. A partir de uma breve análise de manuais de metodologia do trabalhado científico, buscamos apontar como textos veiculados no espaço acadêmico perpetuam a supremacia do conhecimento eurocêntrico. Argumentamos, assim, que a escrita é uma ferramenta que sustenta e mantém fortemente a violência epistêmica na universidade, excluindo identidades, subjetividades e saberes outros. Nesse sentido, apontamos a interculturalidade crítica como uma perspectiva viável para construção de uma universidade mais democrática e comprometida com a pluralidade cultural e epistemológica existente no mundo.

PALAVRAS-CHAVE: Colonialidade do saber. Escrita acadêmica. Interculturalidade Crítica.

1 Mestranda em Estudos Linguísticos no Programa de Pós-graduação em Letras e Linguística da Universidade Federal de Goiás. Goiânia, GO, Brasil. E-mail: naiaracristn@gmail.com.

2 Doutor em Linguística pela Universidade Federal de Goiás. Professor Adjunto no curso de Licenciatura em Educação Intercultural da Universidade Federal de Goiás. Anápolis, GO, Brasil. E-mail: marquesandre@yahoo.com.br. 


\section{ABSTRACT}

In this article, we discuss how the Eurocentric model of knowledge production marginalizes other epistemologies in the name of the alleged neutrality and rationality established by the geopolitics of knowledge in the modern/colonial world. We are thus interested in discuss how epistemic violence is perpetuated, mainly, by the structuring of the university itself. From a brief analysis of methodology manuals of scientific work, we seek to point out how texts transmitted in academic space perpetuate the supremacy of Eurocentric knowledge. We argue, therefore, that academic writing is a tool that sustains and strongly maintains epistemic violence in the university, excluding other identities, subjectivities, and knowledge. In this sense, we point to critical interculturality as a viable perspective for building a more democratic university committed to the cultural and epistemological plurality in the world.

KEYWORDS: Coloniality of Knowledge. Academic writing. Critical interculturality.

\section{Introdução}

Com a colonização da América, é instaurada uma matriz colonial do poder constituída, segundo Mignolo (2010), por uma estrutura complexa de níveis entrelaçados que exerce o controle da economia, da autoridade, da natureza e dos recursos naturais, do gênero e da sexualidade e da subjetividade e do conhecimento. Esta estrutura de poder não se findou com a descolonização política dos territórios colonizados, mas continua atuante e se renova até a contemporaneidade, em múltiplas e variadas formas de colonialidades. A colonialidade do saber, como uma das mais pervasivas dimensões dessa matriz de poder, se mantém e é atualizada no privilégio de uma perspectiva eurocêntrica de produção do conhecimento - racialmente hierarquizada - que elimina outras racionalidades e outras formas de conhecimento (WASH, 2008, p.137). Esse privilégio epistemológico é perpetuado na contemporaneidade, sobretudo em espaços de produção e transmissão de conhecimentos, como a universidade. Buscamos, nesta direção, problematizar como a colonialidade do saber opera e corrobora com as violências epistêmicas que são geradas e mantidas pela geopolítica do conhecimento, tendo em 
vista que o legado do colonialismo e do imperialismo, como aponta Porto-Gonçales (2005, p.3), não se limita à desigualdade e à injustiça social, mas se estende ao legado epistemológico eurocêntrico que não nos permite pensar o mundo a partir de outras epistemes.

O conhecimento ocidental, calcado em um pensamento canonizado pela ciência moderna, perpetua o ideal de racionalidade que deve ser priorizado na produção do conhecimento científico. Castro Gómez (2005), que critica veemente o pensamento filosófico ocidental, se refere a esta posição de privilégio como a hybris do ponto zero, que seria, alegadamente, uma lente transparente para a construção do conhecimento. Segundo o autor (2005, p. 25), a hybris do ponto zero se refere a um ponto absoluto de partida para a produção de conhecimento, situado numa posição hegemônica de poder, a partir do qual "o observador faz tábula rasa de todos os conhecimentos aprendidos previamente".

Nessa perspectiva, podemos afirmar que a hybris do ponto zero delimita fronteiras em relação à legitimidade dos conhecimentos, visto que é considerado um começo epistemológico absoluto. Isso significa dizer que instituir é, ao mesmo tempo, localizar-se no ponto zero e ter o poder de representar e construir uma determinada visão de mundo alegadamente universal e a única, reconhecida como legítima (CASTRO-GÓMEZ, 2005, p. 25). Neste sentido, o ponto zero hierarquiza, subalterniza e silencia a pluralidade de epistemologias existente no mundo, assim como institui performaticamente, ao mesmo tempo em que hierarquiza as identidades e subjetividades dos sujeitos colonizados. O ponto zero gera, assim, uma das mais violentas consequências da colonialidade do saber, uma vez que, conforme Mignolo (2011, p. 80), toda forma de conhecer que não se conforma à epistemologia do ponto zero é posicionada no passado, sendo, portanto, situada em categorias inferiorizantes, como as do mito, da lenda, do folclore ou do conhecimento "tradicional".

É precisamente por esta estratégia de poder que o pensamento científico eurocentrado se posiciona como a única forma válida de produção de conhecimento e a Europa, retoricamente instituída como auge civilizacional, adquire privilégio, ao mesmo tempo em que justifica sua hegemonia epistemológica sobre todas as culturas do mundo(CASTRO-GÓMEZ, 2005;MIGNOLO, 2011).As experiências que sobreviveram a esse epistemicídio são contemporaneamente submetidas à epistemologia dominante, sendo, muitas vezes, autodefinidas como saberes locais, utilizados como matéria prima 
para avanços científicos (SANTOS E MENEZES, 2009, p. 10). O epistemicídio é, dessa forma, não somente uma perda gnoseológica, mas uma perda ontológica, visto que os colonizados foram colocados como seres inferiores que produzem saberes, também, considerados inferiores (SANTOS E MENEZES, 2009, p. 10).

A universidade como instituição que legitima a produção do conhecimento científico é representativa no cenário da perpetuação da colonialidade do saber, visto que, ao longo dos séculos, tem difundido padrões eurocêntricos, que marcam as formas de produção do conhecimento. Desse modo, a geopolítica do conhecimento, instaurada pela modernidade/colonialidade, funciona como uma violência epistêmica que tem colocado os povos colonizados em lugares específicos, os concebendo como seres incapazes de produzir conhecimento válido para a modernidade. Conforme Mignolo (2010, p. 37), utilizamos o termo geopolítica do conhecimento para fazer referência à localização geohistórica e à autoridade das enunciações epistemológicas hegemônicas, bem como à atribuição de posições subalternizadas às enunciações que foram/são negadas e desvalorizadas pelas políticas imperiais do conhecimento, posições que correspondem, respectivamente, à Europa e aos territórios colonizados e, naturalmente, às suas populações.

Alçando-se à universalidade, essa geopolítica inviabiliza a legitimidade das outras narrativas e massacra todo o mosaico cultural e epistemológico que constitui as sociedades pós-coloniais. Os efeitos da colonialidade do saber são, assim, desastrosos para todos os povos que vivenciam de maneira mais contundente as consequências da colonização, ou seja, a colonialidade, e se tornam ainda mais salientes na contemporaneidade intercultural pós-colonial, quando, cada vez mais, corpos, histórias, experiências e conhecimentos subalternizados passam a ocupar espaços nos centros legitimados de produção de conhecimento, como são as universidades.

No que diz respeito, especificamente, ao enfrentamento da colonialidade do saber, nos afiliamos a alternativa proposta por Mignolo (2010) de um desprendimento epistêmico, compreendido como um importante caminho para a descolonização epistemológica, de modo a gerar "uma nova comunicação intercultural, um intercâmbio de experiências e significações, como base para uma outra racionalidade que possa pretender, com legitimidade, alguma universalidade" (MIGNOLO, 2010, p. 16) e, ainda, "aportando os conhecimentos adquiridos por outras epistemologias, outros 
princípios de conhecer e de entender e, assim, outras economias, outras políticas, outras éticas" (MIGNOLO, 2010, p. 17) e que conteste, por exemplo, a racionalidade e a lógica que direcionam as pesquisas; os critérios de legitimidade do conhecimento científico, visto como universal; e, de modo geral, a própria estrutura colonizada e colonizadora das universidades, assim como de seus mecanismos de poder, como a própria "escrita acadêmica".

\section{A estruturação da universidade eurocêntrica}

Como apontado na seção anterior, compreendemos que a universidade perpetua a colonialidade do saber ao reproduzir a ideia da universalidade do saber eurocentrado, em nome da lógica racional que funciona como critério para a validação das pesquisas científicas. Propomos, dessa maneira, nesta seção, problematizar como a universidade eurocêntrica promove a violência epistêmica.

Castro Gómez (2007) argumenta que, tanto na dimensão epistemológica como em sua estruturação, a universidade está inserida na estrutura triangular da modernidade. A estrutura triangular da modernidade, segundo Mignolo (2010), faz referência à colonialidade do ser, à colonialidade do poder e a colonialidade do saber. Nesse sentido, Castro Gómez (2007) destaca que há uma estrutura arbórea do conhecimento e da universidade que é representada pelo pensamento disciplinar. Isso significa dizer que essa estrutura hierárquica das disciplinas marca a diferença entre campos de saber e delimita fronteiras epistêmicas que não podem ser transgredidas (CASTRO GÓMEZ, 2007, p. 81). Ao traçar essas fronteiras epistêmicas, o pensamento disciplinar cria cânones em grande parte baseados numa matriz eurocêntrica - que devem ser usados como referências básicas para validação de pesquisas científicas.

Assim, como afirma Lander (2000), há na universidade diversas formas de reprodução das perspectivas hegemônicas como, por exemplo, a formação profissional recebida pelos alunos, os textos que circulam o espaço acadêmico, a estrutura dos programas de pósgraduação, as avaliações aplicadas e os parâmetros de reconhecimento dos profissionais que trabalham na educação superior. Na mesma perspectiva, Suárez-Krabbe (2011, p.191), ao discutir a necessidade da descolonização das metodologias nas pesquisas antropológicas, 
argumenta que, na própria universidade, encontramos expressões de um apartheid global, representado por um aparato seletivo que funciona em prol da manutenção das estruturas coloniais de poder, atuando por várias formas de "controle das fronteiras".

Suárez-Krabbe (2011) ainda acrescenta que esses regimes ditatoriais das universidades são constituídos por pesquisadores que, mesmo situados fisicamente no Sul, são intelectualmente dependentes das práticas excludentes do Norte, ou seja, são intelectualmente colonizados. Dessa maneira, o controle das fronteiras diz respeito ao fato de que projetos científicos devem ser adequados aos interesses das elites transnacionais para conseguir financiamentos. No mesmo sentido, há um "patrulhamento" que aponta os critérios que são estabelecidos, a partir da lógica eurocêntrica, para definir o que é conhecimento científico relevante. Corrobora para a manutenção dessa estrutura a "vigilância" sobre quais são os requisitos estabelecidos para os pesquisadores publicarem em revistas específicas que são, também, coordenadas pelos "patrulheiros da fronteira". Nesse sentido, podemos afirmar que há toda uma configuração administrativa que trabalha a favor da manutenção da colonialidade do saber. Todos os mecanismos de "controle de fronteira" são, portanto, formas de garantir a alegada universalidade científica. Confrontar e problematizar tais formas de controle é um dos grandes desafios para enfrentar e subverter a estrutura colonial do saber, ou seja, promover o desprendimento epistemológico.

No cenário brasileiro, por exemplo, podemos afirmar que a busca pela internacionalização tem reforçado o "controle das fronteiras" que, em nome dos "padrões de qualidade" das pesquisas realizadas no nosso país, aponta critérios de cientificidade que direcionam pesquisas e projetos, muitas vezes, definindo o financiamento de bolsas e pesquisas. A própria classificação dos periódicos científicos, dessa forma, aponta para critérios que são usados para classificar a produção científica que é produzida nos programas de pós-graduação.

Rita Segato, em comunicação intitulada "Brasil: Colonialidad, elites y universidad: inversión, gestión, evaluación y la reproducción de uma universidad que no da sus frutos", critica o sistema de avaliação direcionado ao sistema de pós-graduação no Brasil. Nessa discussão, a pesquisadora destaca como a classificação de revistas e programas de pós-graduação começou a priorizar a quantidade de pesquisas publicadas, o nível de impacto e a internacionalização 
em detrimento da qualidade das pesquisas publicadas. Esse modelo imposto pela geopolítica moderno/colonial do conhecimento faz com que pesquisadores e docentes calculem, antes de escrever pelo autêntico interesse, qual tipo de artigo pode ser aceito em uma revista que tenha uma boa pontuação, ou seja, escrevem tendo em vista não os seus interesses, mas a partir de ideias que podem ser aceitas em revistas científicas com maior nota, normalmente as revistas que seguem fielmente parâmetros hegemônicos e altamente excludentes de divulgação da produção científica, seguindo, ainda, o modelo das ciências exatas e naturais, e priorizando o gênero artigo, em detrimento de outras configurações textuais. Baseados na discussão empreendida por Segato, podemos afirmar que tal estruturação, focada em um olhar sempre do e para o Norte e nas línguas e configurações textuais hegemônicas, distancia-nos das redes de interlocuções locais, reforçando o caráter mercadológico a que a "universidade corporativa" tem servido (cf. TLOSTANOVA; MIGNOLO, 2012). As próprias interlocuções locais são, portanto, apagadas academicamente, visto que muitas universidades latinoamericanas não são vistas como atrativas para muitos pesquisadores. Isso fica evidente quando, por exemplo, temos nas universidades periféricas parâmetros que conceituam os programas de pósgraduação por produtividade de pesquisas. Universidades com maior vínculo local e com conceitos considerados inferiores são, dessa maneira, invisibilizadas pela elite acadêmica transnacional localizada intelectualmente no Norte.

Etapa necessária para a descolonização do saber é, assim, a problematização dos critérios de cientificidade que amparam a produção acadêmica e como esses atendem às demandas das diferentes sociedades, ou se eles funcionam, ao contrário, a serviço da manutenção da colonialidade do saber. Como aponta Castro Gomez (2007, p.85), a universidade tem se tornado uma empresa capitalista prestadora de serviços que serve a planetarização do capital, sendo legitimada por sua performatividade, ou seja, pela sua capacidade de gerar efeitos de poder, que está diretamente ligada à produção de conhecimentos úteis para a biopolítica global. Por essa razão, é imprescindível repensar tanto a estrutura colonial como os novos dispositivos de poder que ancoram os pilares das nossas universidades latino-americanas, para que possamos torná-las um espaço aberto à pluralidade de epistemologias que constitui as sociedades do mundo, 
assim como um espaço que funcione, principalmente, a serviço do bem-estar das nossas sociedades, ou seja, a serviço da vida.

\section{Manuais científicos como instrumentos de manutenção da colonialidade do saber}

Até aqui, fizemos apontamentos críticos em relação à geopolítica do conhecimento que nos impede de construir uma universidade mais democrática e pluralista. Nesta seção, buscamos discutir como a manutenção da colonialidade do saber é promovida e preservada, também, por manuais que visam apresentar parâmetros de cientificidade ao trabalho acadêmico. Afirmamos, portanto, que há uma vasta literatura engajada em reproduzir os discursos de universalidade da produção do conhecimento. Propomos, assim, uma breve crítica em relação a essas produções, a partir de manuais de metodologia do trabalho científico, mais especificamente, os de Marconi e Lakatos (2003), Severino (2010) e Köche (2011).

O primeiro ponto que desejamos destacar é como esses manuais são categóricos ao apontar o conhecimento científico como soberano em relação a outros conhecimentos. Marconi e Lakatos (2003), ao apontar a diferença entre conhecimento científico e popular, afirmam que

o conhecimento vulgar ou popular, às vezes denominado senso comum, não se distingue do conhecimento científico nem pela veracidade nem pela natureza do objeto conhecido: o que os diferencia é a forma, o modo ou o método e os instrumentos do "conhecer". Saber que determinada planta necessita de uma quantidade " $X$ ” de água e que, se não a receber de forma "natural", deve ser irrigada pode ser um conhecimento verdadeiro e comprovável, mas, nem por isso, científico. Para que isso ocorra, é necessário ir mais além: conhecer a natureza dos vegetais, sua composição, seu ciclo de desenvolvimento e as particularidades que distinguem uma espécie de outra (MARCONI E LAKATOS, 2003, p.76 Grifos nossos). 
Nessesentido, segundo as autoras, objetosou fenômenospodem ser observados tanto pelos cientistas como por pessoas "leigas", mas o que caracteriza o conhecimento científico é justamente a forma de observação. Além disso, apontam que a "Ciência" preza pelo ideal de racionalidade que, por sua vez, prima pela "sistematização coerente de enunciados fundamentados e passíveis de verificação" por meio de teorias, enquanto o conhecimento comum "é entendido como partes ou 'peças' de informação que são frouxamente vinculadas", possuindo, dessa maneira, uma objetividade racional limitada, pois está ligada à percepção e à ação (MARCONI E LAKATOS, 2003, p.76). A partir dessas colocações, fica nítido que somente a ciência com seu aparato teórico-metodológico oferece uma lente mais transparente e racional em relação aos fenômenos que ocorrem no mundo. Por isso, o conhecimento popular é caracterizado como "superficial", "sensitivo", "subjetivo", "assistemático", "acrítico". Em contraposição ao conhecimento popular, o conhecimento científico é baseado, nessa perspectiva, em teorias que não são meras especulações, mas um conjunto de princípios fundamentais que constituem um instrumento científico apropriado para explicar os fatos (MARCONI E LAKATOS, 2003, p.162). No mesmo sentido, Köche (2011, p. 27) aponta que

[o] poder de revisão e de crítica objetiva do senso comum, portanto, é muito fraco, contribuindo para elevar a sua dependência das crenças e convicções pessoais, restringindo-o a uma subjetividade significativa. Por isso, pelo baixo poder de crítica que dificulta a localização de possíveis falhas, as crenças do senso comum são aceitas por longos períodos de tempo e apresentam uma durabilidade e estabilidade muitas vezes superior às da própria ciência (Grifos nossos).

Como podemos observar, a própria concepção de conhecimento também aponta para a totalização e universalização dos parâmetros da ciência moderna. Severino (2010, p.27-28) destaca que o conhecimento é elemento específico fundamental para construção do destino da humanidade, apontando a educação como "processo mediante o qual o conhecimento se produz, se reproduz, se conserva, se sistematiza, se organiza, se transmite e se universaliza". Nessa linha de raciocínio, o trabalho científico deve ser 
extremamente rigoroso, não havendo lugar para "espontaneísmo", "diletantismo", "senso comum" e "mediocridade", já que se exige a "logicidade" e "competência" (SEVERINO, 2010, p. 212). Como na produção de Marconi e Lakatos (2003), observa-se que, em nome na racionalidade da produção do conhecimento, prioriza-se a lógica, que está completamente distante do conhecimento entendido como "popular" de "senso comum".

A produção de Köche (2011) também é representativa nesta discussão, visto que, nesse manual é mostrada claramente a dicotomia entre conhecimento de senso comum e conhecimento científico: o conhecimento de senso comum é uma consequência que surge a partir da necessidade de resolver problemas da vida prática (conhecimento não planejado), sendo elaborado de forma espontânea e instintiva. Por isso, o autor pontua que esse conhecimento é um "viver sem conhecer", já que ele não apresenta razões ou fundamentos teóricos para demonstrar o uso de soluções e informações para determinados problemas (KÖCHE, 2011, p. 24). Assim, esse conhecimento, conforme o autor, está no "nível superficialmente consciencial", ou seja, sem "aprofundamento crítico e racionalista". Nesse sentido, por ser um tipo de conhecimento que muitas vezes resolve a vida prática das pessoas, é transformado em simples "convicções" e "crenças" que são passadas de geração em geração, o que ocasiona o desconhecimento dos limites de sua validade. É importante ressaltar que tal conhecimento coloca o homem como "espectador demasiadamente passivo da realidade" implicando o "baixo poder de interferência e controle" em relação aos fenômenos apresentados na sua realidade cotidiana.

A crítica ao conhecimento de senso comum também é estendida para a discussão em relação à subjetividade, que é caracterizada por representar uma "objetividade superficial" e "limitada", justamente porque está presa "à vivência, à ação e à percepção orientadas pelo interesse prático imediatista e pelas crenças pessoais" (KÖCHE, 2011, p. 25). A subjetividade, desse modo, é vista como uma forma de estabelecer relações superficiais e vagas com a realidade, proporcionando, na maioria das vezes, uma visão distorcida da realidade. A afetividade e a emoção são, nesta perspectiva, uma lente que embaça a tão prezada racionalidade científica. Dessa maneira, a pluralidade de interpretações é vista como negativa, "fruto do viés utilitarista e imediatista". O senso comum, portanto, é entendido como uma perspectiva de conhecimento que possui "baixo poder 
de crítica" e com "tendências dogmáticas". No entanto, convém indagarmos se os próprios parâmetros de cientificidade e a estrutura disciplinar das universidades não apresentam tendências, também, dogmáticas, visto que a própria construção de cânones, como aponta Castro- Gómez (2007), são marcadamente representações dogmáticas que não podem ser contestadas, visto que fazem parte do conhecimento considerado universal e, portanto, considerado uma verdade universal.

O conhecimento, nesta perspectiva, visa a atingir o ideal de racionalidade (verdade sintática) e objetividade (verdade semântica). $O$ primeiro relacionado à sistematização coerente e lógica do conhecimento a partir de teorias que funcionam como padrão de aceitação ou rejeição (padrões de verdade sintática) por uma determinada teoria ou pela comunidade científica, já o segundo ideal ligado à representação fiel da realidade pelas teorias científicas (KÖCHE, 2011, p. 25). Nesse raciocínio, segundo o autor, convém apontar que a intersubjetividade é exigida pela ciência com o intuito de minimizar os erros que a subjetividade pode trazer à investigação, por isso a intersubjetividade, juntamente com verdade sintática e semântica, consegue propiciar a verdade pragmática do conhecimento científico e, consequentemente, a universalidade e objetividade do conhecimento científico.

\section{A geopolítica da escrita acadêmica e a colonialidade do saber}

A partir do exposto, verificamos que a colonialidade do saber é sustentada por vários mecanismos que estruturam a ideia de conhecimento científico que é mantida nas universidades. Observamos que o próprio conhecimento científico estabelece critérios de cientificidade e universalidade que alicerçam o pensamento disciplinar das áreas do conhecimento. Destacamos, também, que há toda uma estrutura administrativa que, em nome do almejado "padrão de qualidade", funciona a serviço do modelo eurocêntrico de fazer ciência. Ressaltamos, ainda, que há literaturas que circulam no meio acadêmico que veiculam a soberania de uma epistemologia que trata "saberes outros" como conhecimentos de senso comum. Nesta seção, em continuidade à discussão anterior, problematizaremos como as literaturas que abordam a produção de 
textos científicos afirmam a geopolítica do conhecimento, também, ao apresentar concepções de escrita acadêmica universais.

Como podemos observar, especificadamente em Severino (2014, p. 150-151), os trabalhos científicos devem apresentar um estilo "sóbrio" e "preciso", prioriza-se, então, a "clareza" em detrimento de qualquer outra característica estilística. $\mathrm{O}$ autor ainda enfatiza a necessidade da construção de uma ordem lógica, que deve ser entendida sem o impedimento de uma linguagem "hermética" ou "esotérica", pontuando, também, o distanciamento do "verbalismo vazio" e da "linguagem sentimental". Nessa perspectiva, todas as marcas identitárias devem ser apagadas em nome da objetividade e neutralidade científica, que é reforçada quando o autor aponta que a condição existencial de empiricidade e liberdade do homem e as interferências pessoais e culturais colocam em risco a prezada objetividade da comunicação (SEVERINO, 2014, p. 53). Trata-se, em nossa interpretação, da operacionalização, através das práticas de escrita acadêmica, da hybris do ponto zero, que visa a apagar o posicionamento geo e corpo-político dos sujeitos produtores do conhecimento. Este processo de purificação da linguagem científica é parte constitutiva da lógica racionalista eurocentrada, como demonstram, por exemplo, Bauman e Briggs (2003).

Nesse mesmo viés analítico, podemos constatar que Marconi e Lakatos (2003, p.76) enfatizam, também, o ideal de racionalidade marcada por imagem da realidade "verdadeira" e "impessoal" como critério para a construção da escrita acadêmica. A partir disso, conhecimentos de "senso comum" são considerados com uma objetividade limitada, visto que, devido a esse fator, estão diretamente ligados à percepção e à ação. É nítida, portanto, a divisão categórica entre conhecimento popular ou local e o conhecimento científico, sendo aquele considerado "superficial", "sensitivo", "subjetivo", "assistemático" e "acrítico" (MARCONI E LAKATOS, 2003, p. 77). Por isso, em relação à escrita acadêmica/científica, as autoras ressaltam a importância de uma linguagem técnica (cognoscitiva e racional), que preza a impessoalidade, simplicidade, imparcialidade (MARCONI E LAKATOS, 2003, p. 250).

A produção de Köche (2011) também é expressiva em relação à padronização da linguagem científica. Nessa produção, o senso comum é caracterizado por apresentar uma "linguagem vaga" e "baixo poder de crítica". A construção dos conceitos, portanto, é "produto de um uso individual e subjetivo espontâneo que se 
enriquece e se modifica gradualmente em função da convivência num determinado grupo" (KÖCHE, 2011, p.26). No entanto, como frisa o autor, a significação de termos fica dependente de contextos, do nível cultural e da intenção do indivíduo que os utiliza, por isso uma linguagem do senso comum proporciona uma "vaguidade" e "falta de especificidade da linguagem" que impedem a delimitação de significados e o controle na realização de experimentos. Desse modo, a "linguagem vaga" corrobora para "significações imprecisas" e "arbitrárias" vinculada ao uso cultural, reforçando, assim, o "caráter subjetivo do senso comum", que impossibilita a construção de um diálogo crítico. O conhecimento científico, portanto, deve, nessa perspectiva, prezar por uma "linguagem correta", pela "objetividade" e pela "clareza". No entanto, contrapondo essa visão apresentada pelos manuais de metodologia do trabalho científico que vimos até aqui, surgem pesquisas com o interesse de contestar a geopolítica da escrita científica, ou seja, investigações engajadas em uma visão mais sensível em relação à pluralidade da construção dos conhecimentos, destacando como a ideia de "senso comum" e de "conhecimento local" se interseciona com categorias de diferença forjadas pela colonialidade, como a hierarquização racial.

Zavala (2010), por exemplo, destaca, a partir de entrevista a uma estudante universitária quéchua, como as práticas de letramento acadêmico funcionam como um dispositivo de poder que tende ao apagamento de identidades e subjetividades que prima pelo "distanciamento" entre o texto e a estudante. Como podemos observar no relato da aluna quéchua reproduzido por Zavala, é nítido que conflitos identitários perpassam a escrita acadêmica. A aluna aponta que "resiste" aos padrões de escrita acadêmica, não podendo, portanto, colocar suas próprias ideias. Além disso, a "engrenagem" das formas de escrita acadêmica é apontada como alheia a ela. Há, dessa maneira, uma “outra forma de dizer", uma forma que não é aceita pela academia:

me dou conta que resisto muito ao escrever de forma acadêmica, eu não resisto, mas aprendo e vejo que essa forma não entra na engrenagem comigo, não é parte dos meus parafusos e então sinto que tenho um parafuso alheio a mim. Eu podia escrever um texto na forma impessoal, mas sempre que leio ou ponho minha ideia fico incomodada porque estou dizendo 
não da forma como sinto comodidade de dizer às pessoas com quem estou vinculada, mas, sim, sinto comodidade de dizer às pessoas com quem não tenho tanto vínculo nem cultural nem econômico. Eu sinto que meus professores vão estar cômodos porque eu já estou nessa onda mas não me sinto tão cômoda porque queria que meus professores aprendessem a outra forma como vou dizer. (ZAVALA, 2010, p. 82 Grifos nossos).

Da mesma forma, Nascimento (2014), discutindo práticas de letramentos acadêmicos em contexto intercultural indígena, aponta características textuais a partir da escrita de acadêmicos indígenas enfatizando a necessidade do reconhecimento de outras lógicas de conhecimento, linguagem e escrita na universidade. Nesse sentido, o autor (NASCIMENTO, 2014, p. 292) argumenta que esses estudantes, mesmo tendo contato com textos acadêmicos baseados em padrões hegemônicos, deixam características de suas práticas de conhecimentos na construção de textos. Por isso, os processos de pesquisa e escrita são marcados pela voz pessoal, caracterizada pelo tom narrativo, que se mistura a relatos reflexivos e descrições realizadas a partir da interação com anciãos e anciãs indígenas, baseadas nas vivências e realidades dos povos indígenas.

Segundo Castillo (2013), para os povos indígenas, falar e pensar muitas vezes são ações que se entrelaçam, ou seja, são ações inseparáveis, desse modo, as características da oralidade como, por exemplo, a repetição e a reiteração de ideias fazem parte da escrita desses povos. Dessa forma, podemos afirmar que as práticas acadêmicas na universidade é um obstáculo para os estudantes, principalmente porque as práticas ocidentais hegemônicas dão um valor excessivo para a escrita acadêmica, dando ênfase a gêneros que são consagrados academicamente, em detrimento de textos narrativos (CASTILLO, 2013, p. 49).

A partir dessas colocações, é importante indagar se a universidade contemporânea está disposta a legitimar tanto a pluralidade epistemológica dos povos colonizados como as formas de transmissão e difusão do conhecimento que são produzidas por esses grupos marginalizados pela geopolítica do conhecimento. Nesta direção, compreendemos que o grande desafio a ser enfrentado, principalmente pelas universidades latino-americanas, é justamente superar a hierarquização das formas de construção dos conhecimentos. 
Contrapondo-nos às ideias apontadas em Köche (2011), entendemos que linguagens que envolvam as vidas e as realidades dos povos indígenas não são um tipo de linguagem "vaga" ou com "baixo poder de crítica", mas que, ao contrário, demonstram que a subjetividade, a identidade e a formas de produzir conhecimento estão imbricadas de modo inequívoco e imprescindível. Impor formas de produção de conhecimento eurocêntricas a povos que partem de outras epistemes para significar/explicar o próprio espaço, é, portanto, uma violência epistêmica que marca o desejo de universalidade e da supremacia da cultura dominante sobre culturas e povos que são considerados inferiores intelectualmente. Afirmamos, desse modo, que as literaturas hegemônicas focadas em metodologia do trabalho científico que circulam no espaço acadêmico, cotidianamente, reproduzem discursos excludentes que descartam toda a pluralidade de formas de produzir conhecimento existente no mundo.

Há, desse modo, barreiras linguísticas e culturais no sistema de ensino, principalmente universitário, que convoca a necessidade de desenvolver estratégias de acordo com as formas de aprender próprias dos contextos culturais dos estudantes, ou seja, é preciso implementar políticas de equidade educativa que reconheçam a pluralidade existente na sociedade, dando um tratamento pedagógico às diferenças sem anulá-las (ZAVALA E CÓRDOVA, 2000, p.15).

Castillo (2013), ao colocar em pauta as representações sociais, interesses, necessidades e expectativas que alunos afrodescendentes e indígenas possuem em relação à escrita acadêmica, destaca a necessidade de considerarmos que a palavra escrita não possui o mesmo valor para todos os povos e culturas, já que há povos em que a oralidade é fonte de todo conhecimento e ação, principalmente no caso de culturas indígenas. A escrita, desse modo, funciona historicamente como dispositivo de poder que trabalha em prol da exclusão. A universidade colombiana, segundo a autora, é representativa no processo de exclusão das minorias étnicas - principalmente de povos indígenas e afrodescendentes - em processos de ingresso na universidade, além disso, a permanência desses alunos, que conseguem ingressar no nível superior de ensino, ainda é preocupante, visto que as universidades ainda não estão preocupadas, de fato, com a reestruturação de um sistema de ensino mais democrático: 
as universidades só se preocupam em cumprir as leis de cotas de ingresso que são impostas pelo Estado e o que posteriormente ocorra com os estudantes, não é uma preocupação de quase ninguém. Quem sabe a causa [da evasão e da dificuldade para terminar a universidade] tenha a ver com as práticas acadêmicas próprias da Universidade, em que a escrita ocupa um lugar central e o espanhol é a língua oficial, em detrimento de outras práticas, como a oralidade e o uso de línguas indígenas como línguas maternas (CASTILLO, 2007, p.11).

A escrita, portanto, deve ser pensada além do conjunto de habilidades e competências, ou seja, deve ser considerada como uma prática social que é produzida dentro de uma cultura com fins diversos, considerando que existem sujeitos que escrevem, sujeitos que possuem histórias e ideias e que reclamam por reconhecimento (CASTILLO, 2013, p.132). O que vimos anteriormente, a partir de uma breve análise de concepções de conhecimento e de formas de produzir conhecimento veiculadas em alguns manuais, é que, longe de ser uma prática social, a escrita em espaços acadêmicos tem sido considerada simplesmente como uma habilidade sem relação com as histórias das pessoas que escrevem. Por essa razão, entendemos que a escrita acadêmica, sem dúvidas, é uma ferramenta que sustenta e que mantém fortemente a violência epistêmica nas universidades. Zavala e Córdova (2010, p.18) apontam como as diferenças linguísticas exercem uma dominação simbólica a partir da construção de diferenças que são silenciadas. O controle dos recursos linguísticos é, nesse sentido, uma forma de legitimar determinadas práticas comunicativas de grupos dominantes. Para as autoras, o uso do "motoseo" (um uso linguístico de falantes que possuem o quéchua como primeira língua e o castelhano como segunda língua) é visto com inferioridade no Peru, o que aponta para ideologias linguísticas em relação a esse uso, principalmente veiculado pelas instituições de ensino. Para as autoras, quando um estudante é tachado de "ignorante" por ser "motoseo" e falar o quéchua, perpassa a ideia de que é incapaz de pensar de forma coerente por não ter aprendido as convenções ditadas pela escrita acadêmica. Nesse sentido, a discriminação não se estende apenas ao âmbito acadêmico, mas interfere na aquisição de outros recursos sociais. Tais constatações são importantes porque ilustram de forma profícua como os sistemas de ensino reproduzem 
a inequidade social e racial a partir da construção de uma linguagem valorizada e considerada "legítima", falada por falantes "normais". Entende-se, então, que

as discussões sobre quais tipos de práticas linguísticas deveriam ser consideradas "boas", "normais", "apropriadas" ou "corretas" não são neutras nem puramente técnicas, mas são desenvolvidas no marco de orientações ideológicas que estão conectadas a interesses sociais, econômicos e políticos de grupos dominantes da sociedade. Isso ocorre, por exemplo, quando nas universidades são geradas discussões com relação ao uso do quéchua em certos espaços, as variedades do castelhano que usam os estudantes bilíngues ou as práticas letradas - ou formas de ler e escrever - esperáveis na educação superior. Quando se privilegia certas práticas sobre outras há interesses sociais em jogo. Sempre há alguns grupos que ganharão e outros que perderão com a representação da realidade que se consegue impor. (CÓRDOVA E ZAVALA, 2010, p. 46).

A partir da legitimação de práticas acadêmicas como, por exemplo, a legitimação de determinadas concepções de escrita, ocorre a censura do "motoseo" como uma prática de higiene verbal, em que usos linguísticos como o quéchua, o castelhano andino e outras formas de pronúncias são vistas como "incorretas" "primitivas" e "toscas" (CÓRDOVA E ZAVALA, 2010, p. 52). Tal higienização, difundida, também, pelos sistemas de ensino, é representativa na construção de ideologias linguísticas que apontam para uma "limpeza" da linguagem veiculada pelos próprios falantes que almejam "melhorar" e "limpar" a linguagem, numa nítida manutenção da lógica moderna/ colonial (BAUMAN E BRIGGS, 2003). Para Córdova e Zavala (2010), esses discursos representam um controle social de grupos hegemônicos que apregoam uma concepção de escrita e de língua baseadas na utópica "neutralidade" e "tecnicidade", quando, na verdade, camuflam os conflitos em relação à raça, cultura, classe e gênero. Dessa maneira, a higiene linguística para eliminar o "motoseo" não é uma problemática somente linguística, mas aponta para conflitos sociais e raciais, que ficam nítidos quando pensamos que a repulsa pelo "motoseo" também está vinculado a imposição de 
uma identidade ocidentalizada (que faz referência desde a mudança de costumes até a forma de falar) às pessoas que usam o "motoseo" cotidianamente para se comunicar.

A partir dessas considerações, afirmamos que as pesquisas latino-americanas, como as de Castillo (2013), Nascimento (2014) Córdova e Zavala (2010), têm apontado a necessidade de uma mudança na universidade, principalmente em relação às padronizações que ditam e que excluem as diversas formas de produzir conhecimento no ambiente acadêmico. Por isso, de acordo com Sito (2016, p. 255), entendemos que enunciar a pluralidade nos modos de escrita acadêmica é fundamental para a formação mais justa de grupos sociais que foram subalternizados pelo poder hegemônico. Neste sentido, é fundamental criar esforços pela mudança das convenções de produção escrita acadêmica. Nessa lógica, para que possamos subverter a lógica colonial que estrutura as universidades latinoamericanas, é necessário construir uma universidade que consiga, de fato, legitimar práticas de escrita e conhecimentos outros que foram/ são silenciados pelo poder hegemônico. Por isso, como alternativa para subverter a estrutura colonial de poder que guia nossas práticas acadêmicas, propomos a necessidade de uma universidade pautada na interculturalidade crítica, para que, dessa maneira, possamos construir efetivamente uma universidade mais democrática e comprometida com uma educação libertadora.

\section{A interculturalidade crítica como perspectiva para descolonizar a universidade}

Em continuidade à problematização empreendida até aqui, buscamos, nesta seção, discutir como a interculturalidade crítica pode ser um caminho viável para (re)pensarmos a lógica colonial, que tem guiado as práticas acadêmicas nas universidades latino-americanas. Entendemos a interculturalidade crítica, conforme Walsh $(2006 ; 2010)$, como um projeto alternativo de caráter político-social-epistêmicoético e como base para uma pedagogia decolonial que propõe-se como um pensamento "outro", comprometido com as diferentes formas de pensar, sendo, portanto, considerado "pensamento, prática, poder e paradigma de e desde as diferenças, desviando-se das normas dominantes e, ao mesmo tempo, radicalmente desafiando-as, abrindo, assim, a possiblidade para a descolonização" (WALSH, 2006, p. 21). 
Dessa maneira, podemos afirmar que o projeto da interculturalidade crítica e do pensamento decolonial caminham juntos, pois a construção da interculturalidade implica o desprendimento como etapa necessária para

[t]ransgredir, interromper e desmontar a matriz colonial ainda presente e criar outras condições de poder, saber, ser, estar e viver que distanciam-se do capitalismo e da sua razão única. Similarmente, a decolonialidade não terá maior impacto sem o projeto e esforço de interculturalizar, de articular saberes, modos e lógicas de viver dentro de um projeto variado, múltiplo e multiplicador, que aponta para possibilidade não de co-existir, mas de con-viver (de viver "com") em uma nova ordem e lógica que partem da complementariedade das parcialidades sociais (WALSH, 2012, p. 69).

Corrobora para tal afirmação o fato de a interculturalidade, ao contrário de construtos teóricos que foram criados na comunidade acadêmica, ser um conceito que emerge, principalmente, no seio do movimento indígena latino-americano, representando nitidamente uma configuração conceitual que é por si mesma "outra", visto que nasce de um movimento étnico-social e não como parte de um pensamento baseado em legados eurocêntricos ou nas perspectivas da modernidade; e, finalmente, não surge a partir dos centros geopolíticos de produção representativos do conhecimento acadêmico (WALSH, 2006, p. 21-22). Podemos dizer, desse modo, que a interculturalidade visa promover as formas de pensamentos que foram subalternizadas e apagadas pela colonialidade do poder. Como aponta Mignolo (2008), o próprio pensamento decolonial é um pensamento que promove o desprendimento de estruturas coloniais trazendo a lume as possibilidades que foram "encobertas", ou seja, colonizadas e desprestigiadas pelos padrões da racionalidade moderna. Dessa maneira, a perspectiva da interculturalidade crítica pode promover um verdadeiro desprendimento epistêmico, que é fundamental para a construção de uma sociedade mais equitativa.

Como podemos observar em Walsh (2012), Candau (2013), Tubino (2014), a partir da década de 90, surgem na América Latina políticas educacionais direcionadas especificadamente aos povos indígenas eafrodescendentes. Nessadécada, o termo interculturalidade 
começa a ser usado como forma de simplesmente acrescentar a diversidade no sistema e modelos existentes, o que de fato reduz a interculturalidade a um novo multiculturalismo neoliberal (WALSH, 2012 , p.64). Esse olhar em relação à diversidade é chamado por Tubino (2014) de interculturalismo funcional, entendido como um discurso e práxis que servem aos interesses do Estado e do sistema capitalista, por invisibilizar as assimetrias sociais e as relações de poder que subjazem a toda a estrutura colonial de poder. Candau (201, p.154) aponta que, na lógica da interculturalidade funcional, conteúdos relacionados a diferentes culturas são introduzidas nos currículos educacionais, mas sem afetar a "cultura comum" e os conhecimentos e valores que são considerados historicamente universais.

O projeto da interculturalidade crítica, no entanto, aponta para uma política cultural preocupada com uma transformação sociohistórica que vai além do reconhecimento da necessidade de inclusão. Isso significa dizer que esse projeto visa a apontar alternativas para uma civilização e sociedade que convocam uma política e pensamento que além de confrontar a colonialidade do saber, possa de fato propor outra lógica radicalmente oposta àquela imposta pela matriz colonial do poder, uma lógica que ofereça uma alternativa de organização da sociedade, da educação e do governo baseada na ideia de que a diferença não seja vista simplesmente de maneira aditiva, mas como constitutiva das sociedades do mundo (WALSH, 2006, p. 34). Por isso, a interculturalidade crítica pode nos oferecer perspectivas outras para problematizarmos as diferenças e desigualdades construídas ao longo da história contra grupos que foram marginalizados. Como um projeto político-social-epistêmicoético e, também, decolonial, a interculturalidade crítica é um caminho que pode viabilizar a construção de sociedades igualitárias a partir da construção de relações novas entre diferentes grupos socioculturais, empoderando as minorias que foram inferiorizadas historicamente (CANDAU, 2013, p.152). Nessa perspectiva, consideramos que a interculturalidade crítica é fundamental para repensarmos a epistemologia considerada universal que é veiculada em formulações curriculares, para que possamos construir um diálogo com diferentes cosmovisões e saberes que constituem diversos grupos sociais (CANDAU, 2013, p.155).

Nesse sentido, podemos afirmar que, apesar dos avanços que dizem respeito às formas de acesso, ainda impera uma perspectiva 
multiculturalista (interculturalidade funcional), que exclui grupos que foram historicamente subalternizados, visto que, como apontamos anteriormente, há toda uma estrutura eurocêntrica que sustenta os pilares da universidade. Assim, compreendemos que a inclusão de grupos marginalizados pela matriz colonial do poder deve ser repensada e colocada em pauta não a partir da interculturalidade funcional que, conforme Tubino (2014), invisibiliza as assimetrias sociais existentes, perpetuando a estrutura colonial sem questioná-la.

Entendemos, portanto, que a perspectiva intercultural crítica é viável para propormos mudanças significativas que visem a tornar os espaços acadêmicos como lugares de diálogo, troca de saberes e intercâmbio cultural, que abarquem modos de pensar, bem como a pluralidade de conhecimentos produzidos por grupos sociais que são marginalizados por universalismos eurocêntricos, ou, como propõe Mignolo (2010, p.17), que a comunicação intercultural seja, inequivocamente, uma comunicação interepistêmica. A universidade eurocêntrica nunca conseguiu atender às demandas de uma sociedade que sempre foi plural e que, cada vez mais, está presente nos espaços acadêmicos. No entanto, a democratização dos espaços acadêmicos não se limita ao simples acesso de povos indígenas e afrodescendentes às vagas que são garantidas, por exemplo, por meio do sistema de cotas ou de cursos específicos. É fundamental abrir espaços para a pluralidade ao invés de perpetuar a violência epistêmica veiculada pelas visões cientificistas estimuladas, principalmente, pelos sistemas de ensino.

A colonialidade do saber, nesse sentido, usurpa a enunciação dos povos colonizados, por isso, é fundamental o processo de descolonizar o saber a partir de políticas interculturais que nos permitam "falar a partir das nossas próprias vozes, desde nossos próprios lugares e com nossas palavras", propiciando, então, "possibilidades não só de conhecimentos diferentes, mas de sentidos diferentes de existência". Nesta direção, a academia deve aprender o "potencial não só epistêmico, mas sobretudo ético, estético e político" da interculturalidade (ARIA, 2010, p.469).

A interculturalidade, portanto, é uma alternativa viável não só para a reconstrução dos sistemas de ensino que são marcadamente coloniais, mas é um projeto de sociedade que surge a partir de um pensamento fronteiriço, por atores que vivem a colonialidade com seus próprios corpos e subjetividades, que por meio das suas lutas pela vida constroem novas perspectivas tanto de nação como 
de civilização e de existência, almejando transformar a estrutura colonial dominante (ARIA, 2010, p. 462). As universidades latinoamericanas devem, dessa maneira, por meio de interlocuções locais, da práxis pedagógica e da pesquisa criar esforços para a construção de um novo modelo de universidade que possa ser, de fato, mais democrático e que trabalhe em prol da construção de sociedades mais justas, que reconheçam a pluralidade como constitutiva da vida humana.

\section{Considerações finais}

Procuramos discutir, ao longo deste artigo, como as universidades, marcadamente eurocêntricas, trabalham a serviço da matriz colonial do poder. Apontamos, ainda, como a geopolítica do conhecimento, a partir de 1492, instaurou-se no mundo a partir da visão do homem branco e europeu, apagando, desse modo, a pluralidade epistemológica existente no mundo e invisibilizando as formas de produção de conhecimento dos povos que foram colonizados. Vimos, portanto, que colonialidade do saber é hoje perpetuada, principalmente, pela universidade, por meio dos dispositivos de poder que foram configurados para manter a lógica eurocêntrica e universal que ampara os modelos de produção de conhecimento.

Enfatizamos, dessa forma, a necessidade de uma (re) construção das universidades latino-americanas, que só poderá ser reconfigurada, principalmente, a partir dos (as) pensadores localizados nas margens do poder hegemônico. Para isso, apontamos a interculturalidade crítica como um projeto alternativo de carácter político-social-epistêmico-ético e como pedagogia decolonial que pode, de fato, propiciar uma mudança possível nas instituições acadêmicas.

Como escreveu o antropólogo equatoriano Patricio Guerrero Arias em "Corazonar: una antropologia comprometida con la vida”, a interculturalidade só será possível a partir da insurgência da ternura. A diversidade sempre esteve presente em nossos espaços, mas devemos hoje legitimá-la cotidianamente, pois os projetos homogeneizantes e universalistas que visam a uniformizar as diferenças causam intolerâncias e conflitos, que só podem ser combatidos a partir da ternura das diversidades. Essa ternura nos 
permitirá corazonar a vida e abrirá possibilidades para combater e enfrentar a colonialidade do poder, do ser e do saber, para que possamos "imaginar formas diferentes de ser, de fazer, de sentir, de pensar, de imaginar, de dizer, de nomear e significar" (ARIA, 2010, p. 279). É preciso, portanto, lutar contra a colonialidade do poder que transforma a universidade em uma empresa capitalista, eurocêntrica, branca, estruturada a serviço do neoliberalismo. É preciso, dessa forma, corazonar as práticas acadêmicas para que possamos assumir o locus de enunciação que nos é negado cotidianamente pela geopolítica do conhecimento.

\section{Referências}

ARIAS, Patricio Guerrero (2010). Corazonar: una antropología comprometida con la vida: Miradas otras desde Abya-Yala para la decolonzación del poder, del saber y del ser. 1. Equador: Ediciones Abya-Yala.

BAUMAN, Richard; BRIGGS, Charles L. (2003). Voices of Modernity: language ideologies and the politics of inequality. New York: Cambridge University Press.

CANDAU, Vera Maria Ferrão (2013). Educación intercultural crítica: construyendo caminos. In: WALSH, Catherine (orgs). Pedagogías decoloniales: prácticas insurgentes de resistir, (re)existir y (re)vivir. Tomo i: 1. Quito, Equador: Ediciones Abya-Yala.

CASTILLO, Sandra Teresa Soler (2013). Usted ya en la universidad y no saber escribir: escritura y poder en la universidad. Bogotá: Universidad Distrital Francisco José de Caldas.

CASTRO GÓMEZ, Santiago (2007). Decolonizar la universidad. La hybris del punto cero y el diálogo de saberes. In: CASTRO GOMEZ, Santiago. GROSFOGUEL, Ramón. El giro decolonial: reflexiones para una diversidad epistémica más allá del capitalismo global. Colômbia, Bogotá: Siglo del Hombre Editores; Universidad Central, Instituto de Estudios Sociales Contemporáneos y Pontificia Universidad Javeriana.

CASTRO-GÓMEZ, Santiago (2005). La Hybris del punto cero. Ciencia, raza e ilustración en la Nueva Granada (1750-1816). Colombia, Bogotá: Editorial Pontificia Universidad Javeriana.

CÓRDOVA, Gavina; ZAVALA, Virginia (2010). Decir y callar: Lenguaje, equidad y poder en la universidad peruana. 1 ed. Peru, Lima: Fondo Editorial de la Pontificia Universidad Católica del Perú, 2010. 
DUSSEL, Enrique (2005). Europa, modernidade e eurocentrismo. In: Lander, Edgardo (org.) A colonialidade do saber: eurocentrismo e ciências sociais. Perspectivas latino-americanas Buenos Aires: CLACSO. Disponível em: <http://bibliotecavirtual.clacso.org.ar/>. Acesso em: 10 mar. 2017.

KÖCHE, José Carlos (2011). Fundamentos de metodologia cientifica: teoria da ciência e iniciação à pesquisa. 23 ed. Rio de Janeiro, Petrópoles: Vozes.

LANDER, Edgardo (2010). ¿Conocimiento para qué? ¿Conocimiento para quién? Reflexiones sobre la universidad y la geopolitica de los saberes hegemónicos [S.1.: s.n.]. Disponível em: <http://www.ceapedi.com.ar/imagenes/ biblioteca/libros/81.pdf>. Acesso em: 10 mar. 2017.

MARCONI, Marina de Andrade; LAKATOS, Eva Maria (2003). Fundamentos de metodologia científica. $5^{\text {a }}$ ed. São Paulo: Atlas.

MIGNOLO, Walter (2010). Desobediencia epistémica. Retórica de la modernidad, lógica de la colonialidad y gramática de la descolonialidad. Argentina, Buenos Aires: Ediciones del Signo.

MIGNOLO, Walter (2008). La opción de-colonial: desprendimento y apertura. Um manifiesto y un caso. Tábula Rasa, nº 8. Colômbia, Bogotá. Disponível em: $<$ http://revistatabularasa.org/numero-8/mignolo1.pdf $>$. Acesso em: 04 maio 2017.

MIGNOLO, Walter (2011). The darker side of Western modernity: global futures, decolonial options. Durham/London: Duke University Press.

NASCIMENTO, André Marques do (2014). Geopolíticas de escrita acadêmica em zonas de contato: problematizando representações e práticas de estudantes indígenas. Trabalho em Linguística Aplicada, Campinas, v. 53, n. 2, p. 269297. Disponível em: $<$ http://www.scielo.br/scielo.php?script=sci_abstractEpi$\mathrm{d}=\mathrm{S} 010318132014000200002 \mathrm{Elng}=\mathrm{ptEnrm}=$ iso $>$. Acesso em: $\overline{01}$ mar. 2017.

PORTO-GONÇALVES, Carlos Walter (2005). Prefácio (Edição em português) In: LANDER, Edgardo (orgs.). A colonialidade do saber: eurocentrismo e ciências sociais. Perspectivas latino-americanas Argentina, Buenos Aires: CLACSO. Disponível em: <http://bibliotecavirtual.clacso.org.ar/>. Acesso em: 13 set. 2016.

SANTOS, Boaventura de Sousa. MENESES, Maria de Paula (2009). Prefácio. In: SANTOS, Boaventura de Sousa. MENESES, Maria de Paula (orgs). Epistemologias do Sul. Portugal, Coimbra, Portugal: Edições Almedina.

SEGATO, Rita. Comunicação: Brasil: Colonialid, elites y universidad: inversión, gestión, evaluación y la reproducción de uma universidad que 
no da sus frutos. Disponível em: $<\mathrm{https}$ :/www.youtube.com/watch?v=1XOuANRVpsc>. Acesso em: 05 maio 2017.

SEVERINO, Antônio Joaquim (2007). Metodologia do trabalho científico. $23^{\mathrm{a}}$ ed. São Paulo: Cortez.

SITO, Luanda Rejane Soares (2016). Escritas afirmativas: estratégias criativas para subverter a colonialidade em trajetórias de letramento acadêmico. Tese (Doutorado em Linguística Aplicada) - Instituto de Estudos da Linguagem, Universidade Estadual de Campinas. Disponível em: $<$ http:// repositorio.unicamp.br/jspui/handle/REPOSIP/304864>. Acesso em: 11 nov. 2016.

SUÁREZ-KRABBE, Julia (2011). En la realidad. Hacia metodologías de investigación descoloniales. Tabula rasa, $\mathrm{n}^{\circ} 14$. Colômbia, Bogotá. Disponível em: $<$ https://www.noexperiencenecessarybook.com/ad3L/en-la-realidad-hacia-metodolog-as-de-investigaci-n-descoloniales.html>. Acesso em: 14 mar. 2017.

TLOSTANOVA, Madina V.; MIGNOLO, Walter D. (2012). Learning to unlearn: decolonial reflections from Eurasia and the Americas. Columbus: The Ohio State University Press.

TUBINO, Fidel (2004). Del interculturalismo funcional al interculturalismo crítico. In: SAMANIEGO, M.; GARBARINI, C. G. (Comps.). Rostros $y$ fronteras de la identidad. Temuco: Universidad Católica de Temuco. Disponível em: <http://www.pucp.edu.pe/ridei/pdfs/inter_funcional.pdf $>$. Acesso em: 11 mar. 2017.

WALSH, Catherine (2010). Interculturalidad crítica y educación intercultural. In: VIAÑA, Jorge; TAPIA, Luis; WALSH, Catherine. Construyendo Interculturalidad Crítica. La Paz: III-CAB. Disponível em: <www.uchile. cl/.../interculturalidad-critica-y-educacion-intercultural_110597_0_2405. pdf>. Acesso em: 10 mar. 2017.

WALSH, Catherine (2012). Interculturalidad y (de) colonialidad: Perspectivas críticas y políticas. Visão Global, Joaça, v.15, n.1-2. Disponível em: $<$ https://editora.unoesc.edu.br/index.php/visaoglobal/article/view/3412>. Acesso em: 10 mar. 2017.

WALSH, Catherine (2006). Interculturalidad y colonialidad del poder. Un pensamiento y posicionamiento otro desde la diferencia colonial. In: WALSH, Catherine. WALTER, Mignolo. LINERA, Alvaro Garda. Interculturalidad, descolonizacion del Estado y del conocimiento, $1 \mathrm{ed}$, Buenos Aires, Del Signo. 
WALSH, Catherine (2008). Interculturalidad, plurinacionalidad y decolonialidad: las insugencias político-epistémicas de refundar el Estado. Tabula Rasa. Colômbia: Bogotá. Disponível em: <http://www.redalyc.org/articulo. oa?id=39600909> . Acesso em: 10 mar. 2017.

ZAVALA, V. Quem está dizendo isso?: letramento acadêmico, identidade e poder na educação superior. In: VÓVIO, C.; SITO, L.; GRANDE, P. (Orgs). Letramentos: rupturas, deslocamentos e repercussões de pesquisa em linguística aplicada. Campinas: Mercado de Letras, 2010.

Recebido para publicação em fevereiro de 2018. Aceito para publicação em maio de 2018. 